\title{
Effect of Educational Program for Nurses regarding Neonatal Hormonal Changes and Metabolic Stress Response after Surgery
}

\section{Ashgan Ahmed Mahmoud ${ }^{1}$, Mostafa Mostafa Rezk ${ }^{2}$, Faten Shafik Mahmoud ${ }^{3}$ and Amal Abd El-Aziz Abd El-Salam ${ }^{4}$}

(1) Quality Specialist at the Directorate of Health Affairs in Sharkia Governorate, Egypt, (2) Professor of General Surgery, Faculty of Medicine, Benha University, Egypt, (3) Professor of Pediatric Nursing, Faculty of Nursing, Benha University, Egypt, (4) Assistant Professor of Pediatric Nursing, Faculty of Nursing, Benha University, Egypt

\begin{abstract}
Background: The stimulating effect of surgery may be explained by the facts that stress hormones released in response to pain target. Activation of the stress response the endocrine response is activated by afferent neuronal impulses from the site of injury and metabolic changes induced by the stress response are satisfied and to provide an alternate source of metabolic fuel for tissues. Aim of the study: Was to evaluate the effect of educational program for nurses regarding neonatal hormonal changes and metabolic stress response after surgery. Design: Quasi experimental study design was used. Setting: This study was conducted at Surgical Neonatal Intensive Care Units at Specialized Children Hospital in Benha City. Sample: A convenient sample of 60 nurses and a purposive sample of 50 neonates. Tools of data collection: Four tools were used for data collection (Characteristics of children and nurses structured interviewing questionnaire, behavioral observation checklist for neonates, observational checklist to assess nurses' level practice and pain assessment scale). Results: Majority (93\%) studied nurses had competent level of knowledge score in post-educational program, while the majority $(90.3 \%)$ of them had good score of practice post-educational program intervention. Conclusion: Educational program was effective in improving nurses' knowledge and practice after implementation of educational program and more than three quarters $(78 \%)$ of studied neonates had moderate pain in post intervention. Recommendation: Educational program should be integrated into pediatric nursing curricula to enhance knowledge and skills regarding hormonal changes and metabolic stress response after surgery.
\end{abstract}

Keywords: Educational program, Metabolism stress and Neonatal hormonal changes.

\section{Introduction}

Stress is the body's way of responding to any kind of demand or threat. When body sense danger, whether it's real or imagined, the body's defenses kick into high gear in a rapid, automatic process known as the "fight-orflight" reaction or the "stress response. The stress response is the body's way of protecting from any danger. When working properly, it helps stay focused, energetic, and alert. In emergency situations, stress can save life 
giving extra strength to defend in different situation (Fan et al., 2019).

Stress response to surgery causes an increased production of hormones with catabolic function. The impulses travel along sensory nerve roots through the dorsal root of the spinal cord to the medulla in order to activate the hypothalamus (Aceto et al., 2015).

Metabolic disorder is one that gets in the way of the body breaks down food, absorbs nutrients, or handles enzymes. Left untreated, some of these disorders could affect neonate's development. They can cause organ damage or even death. Most of the disorders associated with metabolic syndrome don't, signs and symptoms of diabetes such as increased thirst and urination, fatigue, and blurred vision (Anna, 2020).

Metabolic complications or aberrations induced by stress may upset the delicate metabolic balance of a neonate already involved in the process of adaptation to its postnatal environment (Jeanne et al., 2020). In addition, the normal neonatal nutrient reserves are limited, and the energy consuming processes of rapid growth and maturation occur simultaneously with the additional demands produced by an operation. This difference is borne out by experimental data, which demonstrate a higher morbidity and mortality in neonates than in older children or adults subjected similar procedures. For these reasons, knowledge of specific aspects of the neonatal stress response may be of greater importance in comparison to similar responses in the adult in an otherwise stable environment and is imperative for those providing care to these infants (Wilson et al., 2016).

Metabolic effect of hormonal changes is increased catabolism which mobilizes substrates to provide energy sources, and a mechanism to retain salt and water and maintain fluid volume and cardiovascular homeostasis. Stress constitutes a state of threatened homeostasis triggered by intrinsic or extrinsic adverse stressors is counteracted by physiologic and behavioral responses aiming to maintain/reestablish the optimal body equilibrium (Caroline et al., 2018). The adaptive stress response depends upon a highly interconnected neuron endocrine, cellular, and molecular infrastructure. Components of stress system are the hypothalamic-pituitary-adrenal axis and the autonomic nervous system, which interact with other vital centers in the central nervous system and tissues/organs in the periphery to mobilize a successful adaptive response against the imposed stressor (Constantine et al., 2020).

Nursing education is a professional that consciously and systematically planned and applied through instruction and discipline. The aim of nursing education is to develop the physical, intellectual, social and spiritual abilities of the nurse to provide professional nursing care through all stages of health and illness in best possible ways. Nursing program is a planned usually with knowledge and clinical practice. It contains the theoretical and practical training provided to nurses in order to prepare the nurses for the role as nursing care professional. The educational program is provided by experienced nurses or other medical professional who qualified for the educational tasks (Academic Senate for California Community Colleges, 2018).

Nursing care of the neonates, the nurses play an important role in assessing the level of pain and immediately treating early complication. Moreover, preoperative 


\section{Ashgan Ahmed, Mostafa Mostafa, Faten Shafik and Amal Abd El-Aziz}

evaluation and intra-operative management neonates are extremely susceptible to hypothermia. highlight issues that the surgical or anesthetic team needs to be aware of during the pre-operative period, and to ensure neonates' safety during their journey of care. In addition, unnecessary cancellations or complications due to inappropriate surgery may be avoided, in addition to costs both to the patient and health service (Pritchard, 2012).

Postoperative management of elective surgical neonates begins during the preoperative period and involves the surgical team, anesthetic staff, and allied health professionals. Appropriate monitoring and repeated clinical assessment are required, along with support for all major organ systems, including cardio-respiratory function, renal function and fluid and electrolyte balance, and awareness for signs of early surgical complications such as bleeding and infection

\section{(Ravindra \& Fitzgerald 2012).}

Postoperative wound care is important in preventing wound infection and promotes wound healing. The nurses plays a vital role in pain management and observe bleeding from drain and dressing of wound, the nurse should know the chain of infection and the mood of infection spread. Also, nurses should follow the universal precautions such as; hand hygiene and aseptic technique during wound care, and administer prophylactic antibiotics to prevent wound infections (Mahmoud et al., 2018).

\section{Significance of the study:}

Stress response leads to hormonal changes for most neonates after the surgery, which start from the activated nerve cells and release of hormones and metabolic changes. Hormonal changes and metabolic response may lead to more reactions that may be caused by more stress; the characteristics of this response are increased fluid in the body due to increased metabolism in the early period immediately after surgery. The beneficial effects of this stress response are in providing alternate energy sources to meet metabolic demands as well as to provide essential building blocks for synthetic activities occurring in the postoperative period (Desborough, 2017) so that this study focused on improving nurses' knowledge and their practices and nurses should have the knowledge about the importance of these hormonal changes and its beneficial effect through implementing an educational program on hormonal changes and metabolic stress response.

\section{Aim of the study}

The aim of the present study was to evaluate the effect of educational program for nurses regarding neonatal hormonal changes and metabolic stress response after surgery.

\section{Research hypothesis:}

1. Nurses who receive educational program about nutrition, hormonal changes and metabolic stress response after surgery will have increased knowledge about neonatal hormonal changes and metabolic stress responses on posttest than pretest.

2. Nurses who receive educational program about postoperative nursing care will have improved practices related to hormonal changes on posttest than pretest.

\section{Subject and Methods \\ Setting:}

The study was conducted at Neonatal Surgery Intensive Care Units (NSICU) at 
Effect of Educational Program for Nurses regarding Neonatal Hormonal Changes and Metabolic Stress Response after Surgery

Specialized Children Hospital in Benha City.

\section{Subjects:}

A convenient sample of 60 nurses working at the previously mentioned setting were selected regardless of their characteristics. A purposive sample of 50 neonates at the previously mentioned setting regardless of their characteristics

\section{Criteria for neonates:}

\section{Inclusion criteria}

- Undergoing major surgery.

- Neonates in surgical intensive care unit.

- Free from other health problem.

\section{Exclusion criteria}

- Weight less than 2 kilogram.

- $\quad$ Age less than < 37 weeks.

- Infectious diseases as sepsis and hyperbilirubinemia

\section{Tools of Data Collection (pre/post} educational program intervention):

Tool (I): A structured interviewing questionnaire sheet:

It was designed by the researcher in the light of relevant studies and researches (Deutschman \& Neligan, 2016). It was translated into Arabic language and composed of two parts.

Part (1):

(A): It contained with personal data of studied nurses and included (age, sex, educational level, years of experience in pediatric nursing and attendance of training courses related to care of neonates after surgery).

(B): This part contained personal data of the studied neonates from medical sheet such as (gestational age, age on admission, weight on admission and weight during surgery).

\section{Part (2): Nurses knowledge}

(A): This part contained nurses' knowledge regarding hormonal changes and metabolic stress response for neonates after surgery. It contained (9) multiple choices questions.

(B): This part included nurse's knowledge about nutrition for neonates after surgery, It contained (7) multiple choices questions.

\section{Scoring system:}

The studied nurses' answers were compared with a model key answer, where correct answer (1) and incorrect answer (0). The total scores of nurses' knowledge regarding hormonal changes and metabolic stress response were ranged from 0 to 9 , while the total scores of nutrition were ranged from 0 to 8 . The total number of questions was 17 . The total score of nurses' knowledge was calculated and then the percentage scores were obtained by dividing the obtained score over the maximum score and multiplied by 100 was categorized as the following:

- Satisfactory $(85 \% \leq 100 \%)$

- Unsatisfactory $(<85 \%)$

Tool (2): Behavioral observation checklist for neonates. It was adopted from Sanders \& Buckner (2006) to assess signs of neonatal stress. The scale consisted of (11) statements (heart rate, respiratory rate, blood pressure, oxygen saturation, autonomic reflexes, skin changes, motor signs, body movements, anxiety signs, facial signs and vocal signs).

\section{Scoring system:}

The scoring system consisted of two point ranged from Increase (2), Decrease (1). The total scores were ranged from 1 to 22 . 


\section{Ashgan Ahmed, Mostafa Mostafa, Faten Shafik and Amal Abd El-Aziz}

\section{Tool (3): An observational checklist}

It included the following subparts to assess nurses' level of practice regarding hormonal and metabolic stress responses through:

(I): Routine blood samples withdrawal according to neonatal sheets before and after surgery to measured hormonal and metabolic stress responses as plasma concentrations at time points.

(II): General postoperative nursing care, it was adopted from World Health Organization WHO (2003). It was used to assess nurses' practice. It included 5 procedures which are; (hand washing, observation for skin, measure vital signs, and wound area and nutrition skills).

\section{Scoring system:}

The score of each item of nurses' practice was classified into done (1) and not done (0). The total score were ranged from (0-12) of nurses' practice were divided into two categories as the following:

$$
\begin{array}{ll}
\text { - } & \text { Competent }(85 \% \leq 100 \%) \\
\text { Incompetent }(65 \%<85 \%)
\end{array}
$$

\section{Tool (4): Pain Assessment Scale.}

It was adopted from Koot et al., (2003) to assess pain in neonates after surgery. It includes assessment of behavioral and physiological sings (facial expression, cry, arms. legs, and state of arousal, calmness/agitation and breathing pattern).

\section{Scoring system for Neonatal Pain Assessment Scale:}

Scoring system score

No pain $\quad 0<3$

Mild pain $\quad 3<6$

Moderate pain $6<9$

Severe pain $9 \geq 12$

\section{Validity of tools:}

The revision of tools was done through a jury of three experts in field of pediatric nursing. The experts reviewed the tool for its clarity, relevance, comprehensiveness, simplicity and applicability. Tools tested content validity of the designed tools through eliciting opinions of the jury group regarding agreement upon the used tools. This phase took one month from beginning of May 2019 to the end of May 2019.

\section{Reliability of tools:}

The reliability of the developed tools was estimated using the Cronbach's Alpha test to measure the internal consistency of the tools. It was found that, the reliability for the structured questionnaire sheet for assessment of nurses' knowledge was (0.84) and for observational checklists used to assess nurses' practices regarding to hormonal changes and metabolic stress response was $(0.89),(0,91)$ for behavioral signs and $(0.85)$ for pain scale.

\section{Ethical consideration:}

The researcher clarified the aim and expected outcomes of the study to the studied nurses before their participation in order to obtain their acceptance. The studied nurses were informed that the study is harmless and all the gathered data are confidential and are used for the research purpose only. Participation in the study was voluntary and nurses were informed that they have the right to withdraw at any time of the study. An oral consent was taken from nurses. 
Pilot study:

A pilot study was conducted to examine the applicability, clarity and feasibility of the study tools to determine the time needed for each tool to fill it. It was carried on $10 \%$ of the total subjects, (6) nurses they were excluded and (5) neonates were excluded from the present study to avoid sample bias. In the light of pilot study analysis, a modification was done and last form was developed. This phase took one month from (beginning of June 2019 till the end of June 2019).

\section{Field work:}

The educational program was implemented to achieve the aim of the current study through these phases; Assessment, planning, implementation and evaluation phase. The educational program was lasted from July 2019 to the end of December 2019 covering 7 month.

\section{Assessment phase}

Assessment phase involved interviews with nurses to collect baseline data. The researcher was available at the study setting Surgical Neonate Intensive Care Unite at Specialized Pediatric Hospital in Benha city, three days/ week;(Saturday, Monday and Tuesday) from 11:00 AM and extended to 1:30 PM and it tooks about 14 weeks to collect data of knowledge. At the beginning of interview the researcher welcomed each nurse, explained the purpose, duration and activities of the study take oral consent. The data of neonates undergoing hormonal changes and metabolic stress response after surgery was collected by researcher from medical record 15 minutes for each child. The researcher gave the studied nurses questionnaire for filling it to assess their knowledge in 15 minutes. Each nurse was observed separately during their actual practice of procedures to assess their level of nursing practice in 30 minutes.

\section{Planning phase}

Based on baseline data obtained from assessment phase and relevant review of literature, the educational program was developed by the researcher as indicated by nurses' level of understanding in simple Arabic language. Different methods of teaching were used as modified lecture, brain storming, demonstration, re-demonstration and group discussion. Suitable teaching media included a hand out as well as audio-visual aids, role play and real equipment to help in proper understanding.

\section{Program construction}

The educational program for nurses was designed by the researcher according to the nurses' actual needs regarding neonatal hormonal changes and metabolic stress responses. It was constructed, revised and modified from the related literature to improve the nurses' knowledge and practices regarding neonatal hormonal changes and metabolic stress responses. The contents were prepared according to nurses' level of understanding in simple, organized and scientific Arabic language.

\section{General objective:}

The educational program aimed to improve nurses' knowledge and practice level regarding neonatal hormonal changes and metabolic stress response after surgery. 


\section{Ashgan Ahmed, Mostafa Mostafa, Faten Shafik and Amal Abd El-Aziz}

\section{Specific objectives:}

At the end of this educational program the nurses working in neonatal surgical care units will be able to:-

- Explain purpose of the educational program

- Identify anatomy of the brain

- Identify endocrine system and hormonal changes

- Define stress response

- Mention causes and types of stress

- Discuss pre-operative nursing care

- Explain post-operative nursing care

- Demonstrate steps of wound care

- Demonstrate steps of pre-operative nursing care

- Perform steps of immediate post-operative nursing care

\section{Implementation phase}

Toward the start of the program sessions, a direction to the motivation behind program took place and nurses were informed about the time and place of sessions which were carried out at the neonatal surgical unit lecture room. The studied nurses were divided into 10 groups, each group consist of 6 nurses, the program has taken 9 sessions for each group and were implemented according to nurses' needs assessment and readiness, distributed as the following; (4) session for theoretical part each session ranged from 30 to 45 minutes and (5) session for practical part, each session kept from 45- 60 minutes, 4 days/ weeks in the morning shift. It took about (14) weeks for program implementation. Theoretical part; the first session of program included introduction to the educational program, anatomy and physiology of brain and endocrine system, the second session of program included hormonal changes, metabolic changes and stress response as definition, causes, types. Third session included pain managements. The fourth session focused on nursing care and nursing role.

Practical part concerned with nursing care of neonatal regarding hormonal changes and metabolic stress response after surgery; the first session included importance of preoperative nursing care, the second session included diagnostic function and managing situations, third session included knowledge about pre-operative nursing care. Then the fourth session included post-operative nursing care; wound care and nutrition skills for neonatal after surgery. Finally the fifth session focused on ensuring nursing role for neonatal hormonal changes and metabolic stress response. These sessions were repeated to each subgroup of nurses.

\section{Evaluation phase:}

After program implementation, the post test was carried out to assess nurses' knowledge level and practice of nursing care regarding to neonatal hormonal changes and metabolic stress response after surgery by using the same pretest format and it took 1 month.

\section{Statistical analysis}

The collected data were organized, coded, computerized analyzed and tabulated by using statistical package for social sciences (SPSS) version 20. Numeric data were described using number and percent. Association between categorical variables was tested using Chi-square test. Continuous variables were presented as mean \pm SD (standard deviation) for parametric data. Paired t-test was used to test the significance of some variances. A 


\section{Stress Response after Surgery}

significant level value was considered when $\mathrm{P} \leq 0.001$.

\section{Results:}

Table (1): Showed that, more than one third of studied nurses $(36.7 \%)$ of the age ranged from $(20<25$ years $)$ with mean age $(29.4 \pm 4.3$ years). Concerning years of experience, less than half of them $(43.3 \%)$ had $>5$ years and level of education of studied nurses was more than half $(53 \%)$ had graduated from Health Technical Institute.

Table (2): Showed that, less than three quarters of studied nurses $(70 \%)$ had unsatisfactory knowledge level score on pretest. While, the majority of them (93.3\%) had satisfactory knowledge level score on posttest. Moreover, it was clear from this table that, there was a highly statistical significant where $(\mathrm{P}<0.001)$ improvement in nurses' total percentage level of knowledge score in posttest as compared with pretest.

Table (3): Represented that more than half of studied nurses $(58.3 \%)$ had poor level of practice on pretest. While, the majority of them (90.3\%) had good level of practice on posttest, with highly statistical significant improvement in level of practice on posttest as compared with pretest $(\mathrm{P} \leq 0.001)$.

Table (4): Revealed that most (80\%) of studied neonates had no pain on pretest and only more than three quarters $(78 \%)$ of them had moderate pain level on posttest.

Figure (1): Clarified that the majority $(90.3 \%)$ of studied nurses had good practices and slightly more than half $(58.3 \%)$ of them had poor total practice.

Figure (2): Showed that less than three quarters (70\%) of studied nurses had unsatisfactory level of knowledge on pretest. While, the majority $(93.3 \%)$ of them had satisfactory total level of knowledge on posttest. 
Table (1): Distribution of the studied nurses according to their personal data $(n=60)$.

\begin{tabular}{|c|c|c|}
\hline \multirow[t]{2}{*}{ Item of personal data } & \multicolumn{2}{|c|}{ Studied Nurse $(n=60)$} \\
\hline & No & $\%$ \\
\hline \multicolumn{3}{|l|}{ Age } \\
\hline$>20$ year & 6 & 10 \\
\hline $20<25$ years & 31 & 36.7 \\
\hline $25<30$ years & 16 & 26.7 \\
\hline $30<35$ years & 7 & 11.7 \\
\hline Mean \pm SD & \multicolumn{2}{|c|}{$29.4 \pm 4.3$} \\
\hline \multicolumn{3}{|l|}{ Gender } \\
\hline Male & 8 & 13.3 \\
\hline Female & 52 & 86.7 \\
\hline \multicolumn{3}{|l|}{ Years of Experience } \\
\hline $1-2$ years & 8 & 13.3 \\
\hline 3-4 years & 6 & 10 \\
\hline $4-5$ years & 20 & 33.3 \\
\hline$>5$ years & 26 & 43.3 \\
\hline Mean \pm SD & \multicolumn{2}{|c|}{$8.2 \pm 5.3$} \\
\hline \multicolumn{3}{|l|}{ Level of education } \\
\hline Secondary school of nursing & 7 & 11.7 \\
\hline Health technical institute & 32 & 53 \\
\hline Technical nursing institute & 6 & 10 \\
\hline Bachelor of nursing & 11 & 18.3 \\
\hline Master & 4 & 6.7 \\
\hline
\end{tabular}

Table (2): Total score of nurses' knowledge regarding neonatal hormonal and metabolic stress responses after surgery at pre and post educational program $(n=60)$.

\begin{tabular}{|c|c|c|c|c|c|c|}
\hline \multirow[t]{3}{*}{ Items } & \multicolumn{4}{|c|}{ knowledge Level } & \multirow[t]{3}{*}{$\chi^{2}$} & \multirow[t]{3}{*}{$P$ value } \\
\hline & \multicolumn{2}{|c|}{ Pre-test } & \multicolumn{2}{|c|}{ Post-test } & & \\
\hline & No & $\%$ & No & $\%$ & & \\
\hline $\begin{array}{l}\text { Satisfying } \\
(85 \% \leq 100 \%)\end{array}$ & 18 & 30 & 56 & 93.3 & \multirow[t]{2}{*}{40.3} & \multirow[t]{2}{*}{$<0.001 * *$} \\
\hline Not satisfying $(<85 \%)$ & 42 & 70 & 4 & 6.7 & & \\
\hline
\end{tabular}




\section{Stress Response after Surgery}

Table (3): Total score of the nurses' practice regarding educational program for neonatal hormonal changes and metabolic stress response after surgery $(n=60)$.

\begin{tabular}{|c|c|c|c|c|c|c|}
\hline \multirow[t]{3}{*}{ Items } & \multicolumn{4}{|c|}{ Nurses' practice } & \multirow{3}{*}{$\chi^{2}$} & \multirow{3}{*}{ P-value } \\
\hline & \multicolumn{2}{|c|}{$\begin{array}{c}\text { Pre-educational } \\
\text { program }\end{array}$} & \multicolumn{2}{|c|}{$\begin{array}{c}\text { Post-educational } \\
\text { program }\end{array}$} & & \\
\hline & No & $\%$ & No & $\%$ & & \\
\hline Good $(85: \leq 100)$ & 9 & 15 & 54 & 90.3 & \multirow{3}{*}{70.0} & \multirow{3}{*}{$0.001^{* *}$} \\
\hline Average $(65:<85)$ & 16 & 26.7 & 5 & 8.3 & & \\
\hline Poor $(<65)$ & 35 & 58.3 & 1 & 1.7 & & \\
\hline
\end{tabular}

Table (4): level of neonatal pain.

\begin{tabular}{|c|c|c|c|c|c|c|}
\hline \multirow[t]{2}{*}{ Items } & \multicolumn{2}{|c|}{$\begin{array}{c}\text { Pre } \\
\text { intervention }\end{array}$} & \multicolumn{2}{|c|}{$\begin{array}{c}\text { Post } \\
\text { intervention }\end{array}$} & \multirow[t]{2}{*}{$\chi^{2}$} & \multirow[t]{2}{*}{$P$ value } \\
\hline & No & $\%$ & No & $\%$ & & \\
\hline No pain $(0<3)$ & 40 & 80 & 2 & 4 & \multirow{4}{*}{2.30} & \multirow{4}{*}{$>0.001 * *$} \\
\hline Mild pain $(3<6)$ & 8 & 16 & 11 & 22 & & \\
\hline Moderate pain $(6<9)$ & 2 & 4 & 39 & 78 & & \\
\hline Sever pain $(9 \geq 12)$ & 0 & 0 & 8 & 16 & & \\
\hline
\end{tabular}

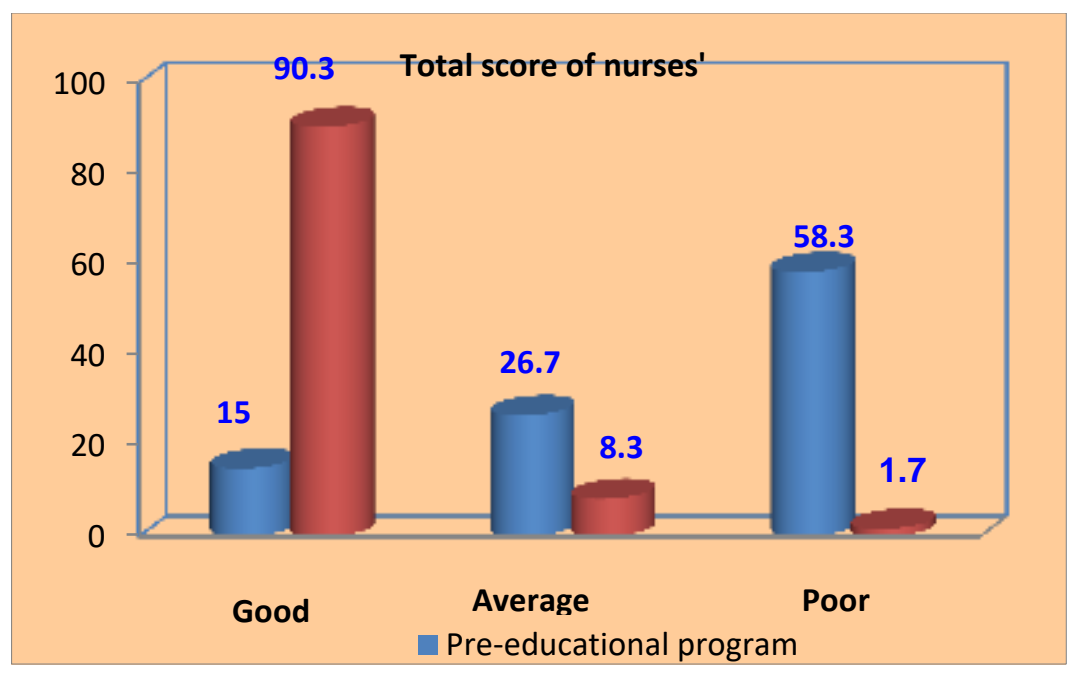

Figure (1): Total score of the nurses' practice regarding educational program for neonatal hormonal changes and metabolic stress response after surgery $(n=60)$. 


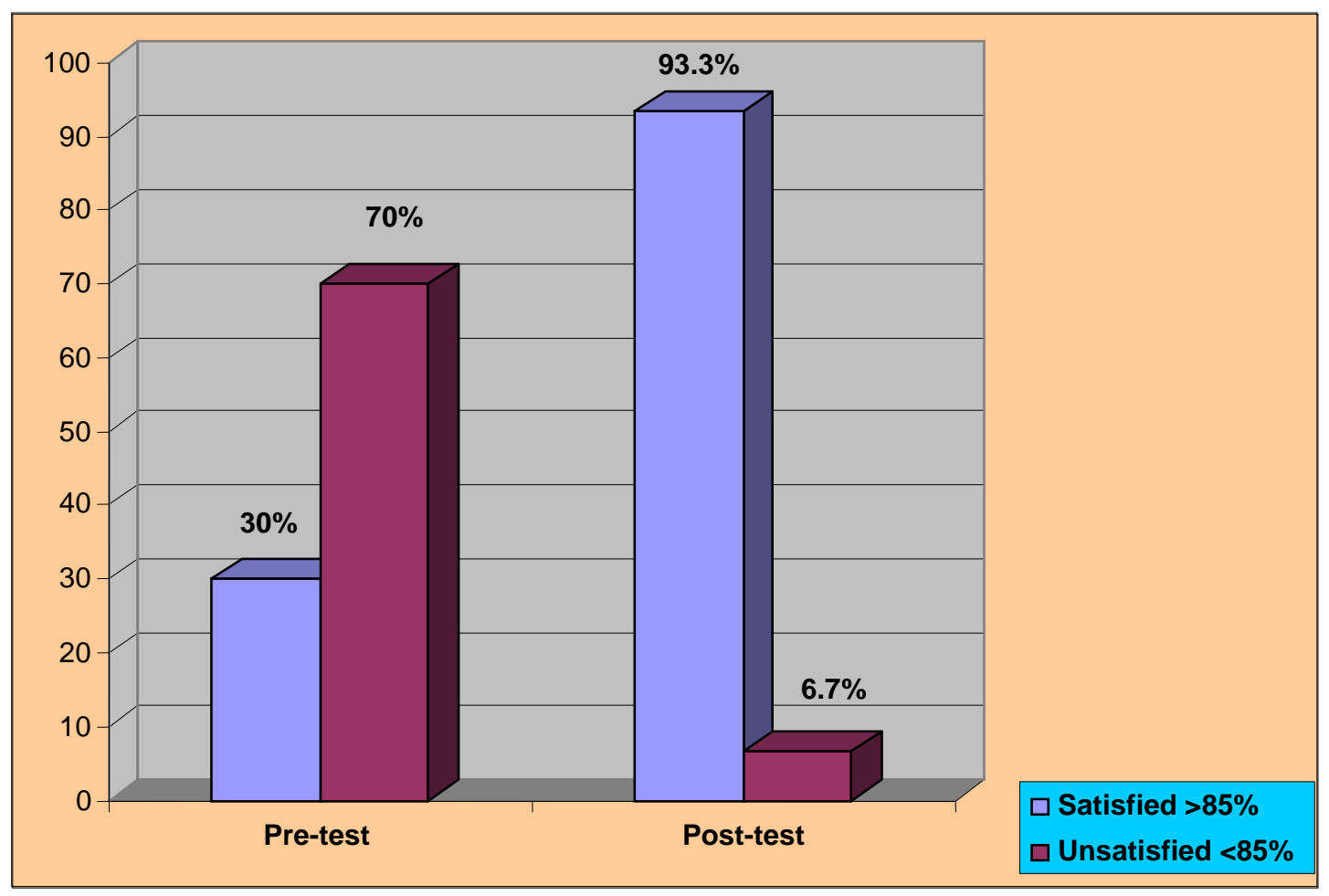

Figure (2): Total score of nurses' knowledge regarding neonatal hormonal and metabolic stress responses after surgery (pre \& post educational program) $(n=60)$.

\section{Discussion}

The nurse plays a pivotal role in the management of providing care for neonatal hormonal changes and metabolic stress responses after surgery. The current study was carried out in neonatal surgical intensive care units at Specialized Children Hospital in Benha city.

Regarding to nurses' characteristics, the present study revealed that more than one third of studied nurses their age ranged between $20<$ 25 years. These finding is supported with study of Zainel, (2014) who found that the majority of nurses in the study, group their age group were ranged between $20<25$ years in NSICU.

According to educational level of studied nurses, the results of current study showed that near to half of the staff nurses had secondary nursing school (Diploma). This study was conducted with study of
Mahmoud, (2015) that reported that the level of secondary school in nursing made the highest score in his study Related to nurses' years of experience, findings have revealed that the number of years of experiences is $>5$ years where $43.3 \%$ of the nurses in the study group.

Concerning nurses' knowledge the current study showed that the majority of nurses had complete answer on posttest. This study was supported by Hassanin \& Mohammed, (2016) they claimed that the majority of studied nurses had poor knowledge before implementing the educational program but after implementing the educational program nurses had higher level of knowledge.

These findings were parallel to the findings of Mahmoud, (2015) who conducted a study about" The Effect of Developmentally 
Supportive Care Training Program on Nurses' Performance and Behavioral Responses of Newborn Infants", at Benha University, Egypt. It was found that the majority of NICU nurses had poor knowledge regarding developmental supportive care. On the contrary, Abdullah, (2016) conducted a study about "knowledge and attitudes of neonatology nurses towards developmental care at Yogyakarta, Indonesia", it was found that $90.62 \%$ of nurses answered correctly questions about definition of developmental care, and stated that neonatal nurses have moderate knowledge of developmental care. The researcher attributed this contradiction to cultural difference and to different health care attitude and practices.

However, nurses had higher levels of knowledge on posttest than pretest. This result is in agreement with a study implemented by Hussein \&Jaddoue, (2015) Also, it was consistent with Hassan\& Hassan (2012); Naseer, (2013)and Shamran \& Hamza, (2016) They mentioned that there were highly significant difference about nurses' knowledge in post-test between study and control groups.

In the light of the study, the average knowledge about essential newborn care was majority. This is lower compared to study conducted in India Malhotra et al., (2014). The discrepancy could be due to the difference in in-service training. But this knowledge is higher than that of Khartoum Naseer, (2013) and Ethiopia Ricca and Rawlins, (2011). In this study, the majority of the respondents had good knowledge and lowest had poor knowledge. This is relatively higher compared to Egypt Fattah et al., (2012), Uganda Ayiasi et al., (2014) and India Malhotra et al., (2014). This discrepancy in level of practice could be due to methodological difference. The slight difference in knowledge might be due to difference between study participants in which only nurses participated in case of study conducted in Egypt and it included nurse assistants in case of Uganda.

The reason of this difference might be difference of educational level of study participants leads to knowledge difference. On the other hand the study finding is higher compared to study done in Ethiopia Ricca \& Rawlins, (2011) and in other study in Ethiopia Koru, (2013). This difference might be time gap between these studies.

Similarly study in Egypt done by Fattah et al., (2012) revealed that, there was a significance relationship between nurses education and their knowledge, while a negative correlation were found regarding to their years of experience. Compared to that of Egypt Fattah et al., (2012), no significance difference between nurses' knowledge and practices and the possible reason might be difference of study participants.

The results of current study contrast with Shamran \& Hamza, (2016) who shows that no significant difference between pre-test and post-test scores of control group members and the nurses knowledge among the control group didn't changed in post test, and stabilized in all their knowledge measures.

As regarding the studied nurses' practice, the result of the present study 


\section{Ashgan Ahmed, Mostafa Mostafa, Faten Shafik and Amal Abd El-Aziz}

showed that the majority of nurses had good total percentages score of practice post educational program intervention, with highly statistical significant improvement in nurses' total percentages score of practice post-educational program intervention than pre-educational program intervention. This finding may be due to nurses need continuous on job training to update their performance regarding nutrition. These findings was supported by the Khan et al., (2012) who study assessment of knowledge and skills of nurses they found that the nurses have poor knowledge and skills regarding hormonal changes after surgery.

Regarding measuring the degree and level of pain for neonates the present study showed that more than three quarters of them had moderate pain level in post intervention. This finding supported by Ibrahim (2011), who studied that assessment of pain with different neonatal procedures of Zagazig University, found level of pain in neonates is mild when a score of them was less while pain was severed when the score was high.

Finally, it can be concluded from this study that nurses had knowledge deficits regarding neonatal hormonal changes and metabolic stress responses after surgery before implementing the program. Possible reasons for this finding may include limited formal lectures on neonatal hormonal and metabolic stress responses after surgery in formal education. But after implementing program, the studied nurses' knowledge scores regarding neonatal hormonal and metabolic stress responses after surgery had significantly improved. This finding were in accordance with Christoffel et al., (2016), who demonstrated the benefits of educational programs and that they can positively change the knowledge of healthcare professionals regarding pain management.

\section{Conclusion}

Nurses' knowledge and practice improved after educational program regarding nutrition, hormonal changes and metabolic stress response, the majority of studied nurses had satisfactory knowledge level in posteducational program, nurses' practice for technique of blood samples and postoperative nursing care the majority of studied nurses had a competent total percentage practice score post-educational program and the mostly of studied neonates had no pain in post educational program.

\section{Recommendations}

- Provision in-services training programs in order to update nurses' knowledge and their practice level regarding the neonatal hormonal changes and metabolic stress response.

- Designing and distributing arabic booklets to all nurses who are working in neonatal surgical unit including all knowledge and pre/postoperative nursing care for neonates.

- Further research; the study should be replicated on a large random sample in different settings for the generalization of the obtained results.

\section{Reference}

Abdullah, R. (2016). Knowlwdge and attitude of neonatology nurse towards developmental care. A state of mind.www. Pediatrics.org. Accessed on 21/1/2019 at 11 pm. 
Effect of Educational Program for Nurses regarding Neonatal Hormonal Changes and Metabolic Stress Response after Surgery

Academic Senate for California Community Colleges. (2018). p. 2-3. Retrieved March 14, 2020. Accessed on 21/3/2020 at $12 \mathrm{pm}$.

Aceto, P. Lai, C. Dello, R. C. Perilli, V. Navarra, P. and Sollazzi, L. (2015). Stress Response to Surgery, Anesthetics Role and Impact on Cognition Rome, Available at http:www.dx.doi.org, Italy, Accessed: July 13, 2019.

Al-Hamza, A. \& Nasir, K. (2017). Effectiveness of an Educational Program on Nurse's Knowledge about Managing of Respiratory Distress Syndrome on Pediatric Units at Al-Diwaniyah City Hospital. International Journal of Scientific and Research Publications; 7(9): 245-249. Accessed on 8/12/2019.

Alshvang, S. (2018). Preoperative Nurses' Teaching for Open Heart Surgery Patients, published thesis, College of Health Sciences, Walden University; 4: 43. Accessed on 22/11/2019 at $11 \mathrm{PM}$.

Anna,

M.D.

(2020).

NeoReviews October, 21 (1) e649e662; DOIhttps:/ /doi.org/10.1542/neo.21-10-e649. accessed on 3/3/ 2019 at 10:15 am.

Ayiasi, R.M. Criel, B. Orach, C.G. Nabiwemba, E. \& Kolsteren, P. (2014). Primary healthcare worker knowledge related to prenatal and immediate newborn care: A cross sectional study in Masindi, Uganda. BMC Health Serv Res 14: 1-11.

Caroline, J. Schmeling, M.D. Arnold, G. \& Coran, M.D. (2018). Pediatric Surgery, Mott Children's Hospital and University of Michigan School, Ann Arbor, Michigan, Journal of Parenteral and Enteral Nutrition; Vol.15. No: 2, P.P:215-238.

Christoffel, M.M., Castral, T.C., Dare, M.F.,
Montanholi, L.L. and Scochi, C.G. (2016). knowledge of healthcare professional on the evaluation and treatment of neonatel pain. Rev bars enferm 69(3): 516-22.

Constantine, J.A. McLean, S.R. \& Dunne, T. (2020). Enteric nervous system development: migration, differentiation, and disease. Am J Physiol Gastrointest Liver Physiol. Bulletin, 122 (5-6), pp. 855-869.

Desborough, J.P. (2017). The stress response to trauma and surgery, British Journal of Anesthesia, Oxford University, Volume 85, Accessed: 1 July 2000, 9:00 A.M, Pp109117, https:// doi. org/10.1093/bja/85.1.109.

Deutschman ,H. \& Neligan, F. (2016). Effect of Education Program on Nurses' Knowledge and Practice regarding care of Central Venous Line in Pediatric Hemodialysis: evidence-based practice guideline; Egyptian nursing journal, 14(2): 87-99. Available at: http//www.enj.net, accessed: 29/4/2018, 3:30 P.M.

Fan, L. Xue, W. \& Markram, H. (2019). "A Brief History of Simulation Neuroscience". Frontiers, in Neuroinformatics. 13:32. doi:10.3389/fninf.2019. 00032. ISSN 1662/5196. PMC 6513977. PMID 31 133838. Accessed on 5/8/2019 at $12 \mathrm{pm}$.

Fattah, E. Zein, N. A \& Dein, E. (2012). Assessment of quality of nursing care provided immediately after birth at university hospital. Life Sci J 9: 2115-2126.

Hassan, S \& Hassan H.S. (2012). Effectiveness of nursing education program on nurses knowledge and Practice toward Arrhythmia in Kirkuk's teaching hospitals, College of Nursing, University of Bagdad; 152166. Accessed on 14/8/2020 at 11 am.

Hassanin, A.A \& Mohammed, H. (2016). Effect of an Educational program for nurse's 
working at Mansoura University Hospitals on Chest Tube Complications, IOSR Journal of Nursing a nd Health Science (IOSR-JNHS); 5(5): 34-42. Accessed on 7/9/2020 at $12 \mathrm{pm}$.

Hussein, T.H \& Jaddoue, B.A. (2015). Impact of Health Educational Program Upon Nurses' Knowledge Towards Postoperative Wounds Care In Mosul Teaching Hospitals, Iraqi National Journal of Nursing Specialties; 28(2):1-9.

Ibrahim, L. (2011). Assessment of Pain with Different Neonatal Procedures, Unpublished master thesis, Zagazig University, Faculty of Medicine. Accessed on 30/12/2019 at 1:00 pm. Accessed on 4/2/2020 at $12 \mathrm{pm}$.

Jeanne, S. Melinda Smith, M.A., Robert Segal, M.A., \& Lawrence, R. (2020). Hydrocephalus Association; Lippincott Williams and Wilkins; pp; 651-7. Accessed in 5/2019 at 5 PM.

Kankkunen, R. Hong X., Zhao G. \& Zafeiriou, S. (2013). 'Capturing correlations of local features for image representation', Neurocomputing, 184, pp. 99-106 (doi: 10.1016/j.neucom.2015.07.134); Accessed on 14/2/2020 at 4 PM.

Khan, N. Khurshid, Z. Ali, K. \& Tazeen, S.A. (2012). Assessment of knowledge, skill and attitude of oncology nurses in chemotherapy administration in tertiary hospital Pakistan; Received 29 December 2011; revised 8 February 2012; accepted 22 February 2012 Published Online June 2012; Accessed on 30/3/2020 at 5 PM.

Koot, H.M., Boer, J.B \& Van, D.M.(2003).version of the COMFORT Scale, In: "pain assessment in neonates". Edited by: anand k,stevens b. accessed November, 6:00 p.m.

Koru, C. (2013). Newborn care practices at home and in health facilities in 4 regions of
Ethiopia. BMC Pediatr 13:198. Accessed on 21/12/20202 at 2:00 pm.

Mahmoud, A. S. (2015). Effectiveness of Cardiopulmonary Resuscitation Program on Nursing Staff Performance in Emergency Unit at Azadi Teaching Hospital, a dissertation submitted by University of Baghdad / College of Nursing. Published doctorate dissertation.p.p.131-133.

Mahmoud, W. Abdullah, M. \& Islam, M. (2018). Knowledge and practices nurses bout administration of medications by nasogastric tube among critically ill children. Journal of Education and Practices.; 5(2): 137-49. Accessed on 15/10/2019 at $12 \mathrm{pm}$.

Malhotra, S. Zodpey, S.P. Vidyasagaran, A.L. Sharma, K. \& Raj, S.S. (2014). Assessment of essential newborn care services in secondary-level Facilities from two districts of India. J Health Popul Nutr 32: 130-141.

Mohammed, S. A. R., Bayoumi, M. H., \& Mahmoud, F. S. (2018). The effect of developmentally supportive care training program on nurses' performance and behavioral responses of newborn infants. Journal of Education and Practice, 5(6), 134-144.

Naseer, T.F.A. (2013). Assessment of knowledge, attitude and practices of nurse midwives towards immediate care of the newborn in Khartoum state teaching hospitals 2011. J Am Sci 9: 263-270. NICU. Global Journal of Health Science; 8(9): 135. Accessed on 25/12/2020 at 2:00 am.

Parajulee, S. \& Selvaraj, V. (2011). knowledge of Nurses towards Cardiopulmonary Resuscitation in a Tertiary care Teaching Hospital in Nepal, Journal of Clinical and Diagnostic Research. No.5 (8), pp. 1585- 1588 . 
Pritchard, M.J. (2012). Pre-operative assessment of elective surgical patients. Nurse Stand. ; 26(30):51-6. Accessed on 8/12/2020 at $12 \mathrm{pm}$.

Ravindra, P. \& Fitzgerald, E. (2012). Surgical preoperative assessment: What to do and why. Student BMJ cited 2012 September 08 ;

Available/from: http://student.bmj.com/student/ view.article.html?id=sbmj.d7816 . 2012 Jan 12; 20.

Ricca, J \& Rawlins, B. (2011). Quality of care for prevention and management of common maternal and newborn complications: A study of Ethiopia's Hospitals 34-35.

Sanders, L.W. \& Buckner, E.B. (2006). The newborn behavioral observations system as a nursing intervention to enhance engagement in first - time mothers: feasibility and desirability. Pediatr Nurs. 32: 455-459.

Shamran, M. \& Hamza, R. (2016). Effectiveness of Educational Program on Nurses' Knowledge about Management of Patients with Heart Failure, University of Kufa Faculty of Nursing.; 5-7. Accessed on 4/4/2020 at $12 \mathrm{pm}$.

Wilson, J. Singh, B. \& Dutta, S. (2016). Guidelines for Nutrients feeding ; 20 (5): 22941. PMid:24279734 https://doi.org/10.1111/nicc.12065."Cerebrum Etymology". dictionary.com. Archived from the original on October 24, 2015. Retrieved October 24, 2015. accessed on 19/9/2020 at $12 \mathrm{pm}$.

World Health Organization [WHO]. (2003). Surgical care at the district hospital Geneva:http://www.who.int/mediacentre/factsh eets/fuse, accessed 11 February, 2014, 3:30 p.m.
Zainel, H. I. (2014). Effectiveness of Nursing Educational Program on Nurses' Knowledge and Practice about Cardio-Pulmonary Resuscitation in Talafar General Hospital, a dissertation submitted by University of Baghdad / College of Nursing. Published doctorate dissertation. pp. 96-100. 

تأثير برنامج تعليمي للممرضات عن التغيرات الهرمونية والإستجابة التوترية للتمثيل الغذائي لادى الأطفال

أثجان أحمد محمودـ مصطفى مصطفى رزق - فاتن شفيق محمودـ أمل عبدالعزيز عبدالسلام

تحدث الاستجابة التوترية في حالة الصدمات والحروق و العدوى الثنديدة و التمارين الثاقة و ينتج عن

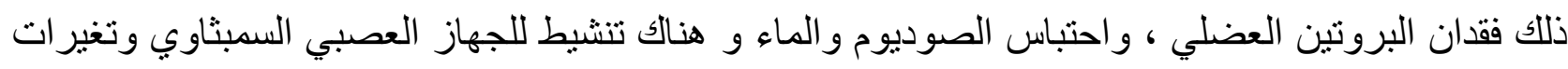

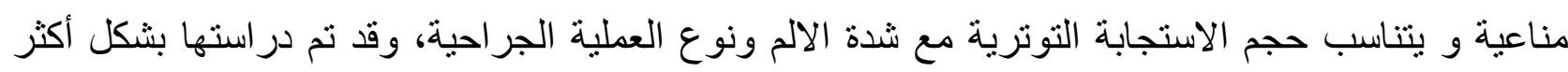

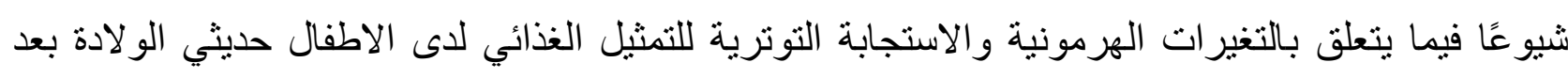

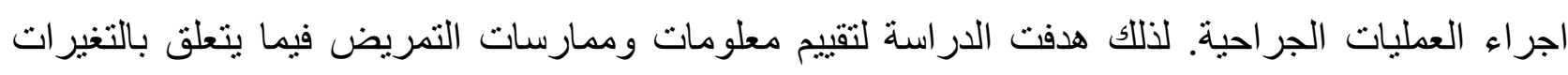
الهرمونية لحديثي الو لادة والاستجابة التوترية بعد العمليات الجر احية.وقد أجريت هذه الدراسة فئة في وحدة العناتية

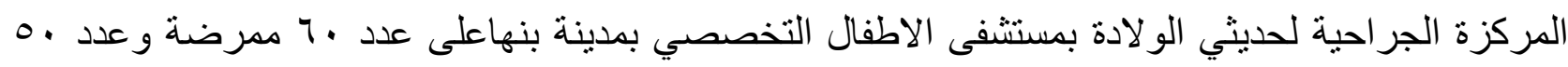

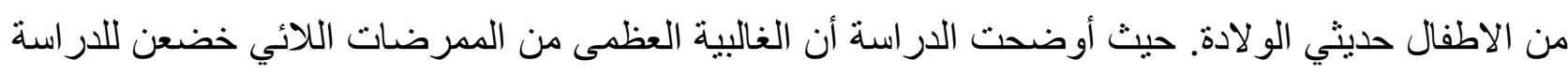

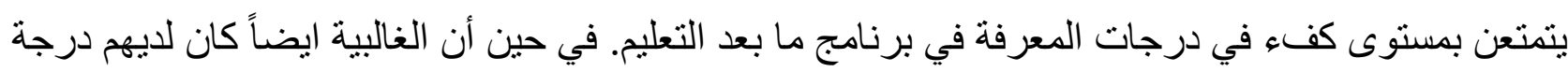

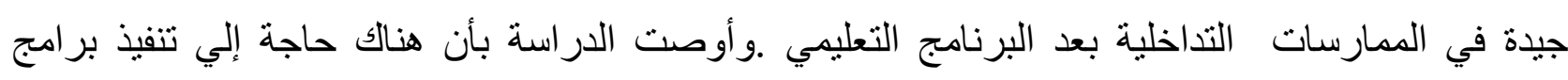

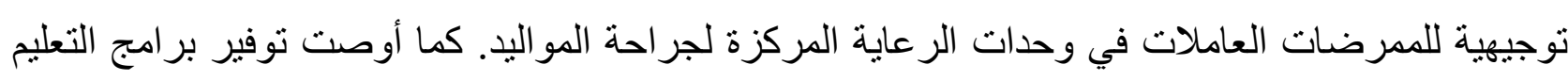
المستمر لتحديث معرفة التمريض ومستوى ممارستهن فيما يتعلق بالتغيرات الهرمونية لحديثي الولادة و استجابة التوترية للتمثيل الغذائي بعد الجراحة. 